\title{
Effects of Kraft Pulping on the Interfacial Properties of Eucalyptus Pulp Fibres
}

\author{
Pedro Fardim ${ }^{*, a}$ and Nelson Durán ${ }^{a, b}$ \\ ${ }^{a}$ Instituto de Química, Universidade Estadual de Campinas, CP 6154, 13083-970 Campinas - SP, Brazil \\ and ${ }^{b}$ NCA-Universidade de Mogi das Cruzes, Mogi das Cruzes - SP, Brazil
}

\begin{abstract}
Os efeitos da polpação kraft nas propriedades interfaciais da polpa de eucalipto brasileiro foram investigados usando titulação com polieletrólito (PT) e medidas de ângulo de contato. Mudanças na composição química da superfície foram avaliadas por espectrometria de reflexão total atenuada no infravermelho (FTIR-ATR), combinada com análise de componentes principais (PCA). O aumento do álcali ativo na polpação provocou a remoção de lignina da superfície, de acordo com FTIR-ATR e PCA. A carga superficial diminuiu enquanto a energia superficial e trabalho de adesão com a água $\left(\mathrm{W}_{\text {ap }}\right)$ aumentaram. O componente ácido-base $\left(\mathrm{W}_{\mathrm{ap}-\mathrm{AB}}\right)$ foi indentificado como o causador do aumento em $\mathrm{W}_{\text {ap }}$. Nossos resultados sugeriram que a remoção de lignina superficial combinada com a exposição de carbohidratos e mobilidade superficial de extrativos são as principais causas das modificações nas propriedades interfaciais geradas pela polpação kraft. A contribuição das propriedades superficiais no desenvolvimento de seqüências de branqueamento e novos produtos de polpa também foram discutidos.
\end{abstract}

The effects of kraft pulping on the interfacial properties of eucalypt pulp fibres were investigated using polyelectrolyte titration (PT) and contact angle measurements. Changes on surface composition were assessed by FTIR-ATR spectrometry combined with principal component analysis (PCA). Surface lignin was removed by increase in active alkali in pulping as indicated by FTIR-ATR and PCA. In parallel, the surface charge decreased while the surface energy and work of adhesion with water $\left(\mathrm{W}_{\mathrm{ap}}\right)$ increased. The acid-base component $\left(\mathrm{W}_{\mathrm{ap}-\mathrm{AB}}\right)$ explained the increase of $\mathrm{W}_{\mathrm{ap}}$. Our results suggested that the removal of surface lignin, exposure of carbohydrates and surface mobility of extractives are the main contributors to modifications of interfacial properties by kraft pulping. The role of interfacial properties on development of bleaching sequences and new pulp products was also briefly discussed.

Keywords: eucalyptus, cellulosic fibre, surface charge, surface energy, work of adhesion

\section{Introduction}

The interfacial properties of fibres are relevant in many interactions during paper manufacture, printing and converting. Reactions with hydrophobic compounds in paper sizing, coating with polymer for use in packaging and fibre-to-fibre bonding in paper are significantly affected by the surface charge. ${ }^{1}$ Adhesion between toner and paper surface in electrostatic printing (laser and photocopy) and mottle in ink-jet printing can also be evaluated in terms of surface energy and work of adhesion..$^{2,3}$ However, it should be mentioned that the determination of interfacial properties in heterogeneous systems such as pulp fibres requires a critical approach. ${ }^{4}$

* e-mail: pfardim@abo.fi

Present Address: Åbo Akademi University, Porthansgatan 3, FIN20500, Turku/Åbo, Finland.
Surface energy and work of adhesion with water are thermodynamic properties usually estimated by measuring contact angle between the fibre surface and certain solvents. In fact, the measured contact angle is an average of local deformations and the energy minimization for the overall system, i.e. an apparent contact angle $\left(\theta_{\mathrm{ap}}\right)$. Thus, the interfacial properties estimated in this case are apparent properties, which can only be evaluated in relative terms.

The interactions between fiber surface and liquids were investigated for hardwood and softwood unbeaten pulps using the Wilhelmy, ${ }^{5}$ inverse gas chromatography (IGC) ${ }^{6}$ and $\theta_{\text {ap }}{ }^{7}$ methods. Determinations of $\theta_{\text {ap }}$ to evaluate wood and fiber materials are not straightforward. Effects of fiber orientation, chemical heterogeneity, surface roughness, swelling and adsorption have been extensively discussed..$^{8-11}$ Correction of morphological and chemical effects by using models was also suggested, but they are quite empirical 
and still require improvements. ${ }^{12-14}$ As a consequence, a strict experimental set-up and certain assumptions are needed. The work of adhesion between water and a solid surface can also be estimated in terms of liquid surface tension and $\theta_{\text {ap }}$ measurements. ${ }^{5}$ The apparent work of adhesion $\left(\mathrm{W}_{\text {ap }}\right)$ is assumed as a combination of two components named Lifishitz-van der Waals $\left(\mathrm{W}_{\mathrm{ap}-\mathrm{LW}}\right)$ and acid-base $\left(\mathrm{W}_{\text {ap-AB }}\right) .{ }^{15}$ The $\mathrm{W}_{\text {ap-LW }}$ component is due to London or dispersion forces across the interface and also includes Keesom and Debye forces. The $\mathrm{W}_{\text {ap-AB }}$ component is due to specific chemical interactions across solid-liquid interface, where hydrogen bonding is considered. Surface energy can be estimated by the empirical method of Zisman ${ }^{16,17}$ that involves contact angle measurements between the solid surface and specific liquids. This technique assumes that if there is no hydrogen bonding at the interface, a plot of $\cos \theta$ versus the surface tension of liquid gives a straight line that extrapolated to unit yields an estimation of surface critical energy.

Estimations of surface charge are presently limited to extrapolation of adsorption isotherms were fiber is used as substrate for adsorption of a high-molar mass polyelectrolyte. ${ }^{18}$ The dimensions of the polymers are supposed to limit the sorption to the external surfaces. However, screening of polyelectrolyte charges in solution, deviation of stoichiometry and presence of nonelectrostatic interactions were reported as drawback for this method. ${ }^{19}$ In this work, we have used a direct titration of surface charges using a high-molar mass polyelectrolyte in deionized water and monitored the streaming potential using a particle charge detector. Surface energy and work of adhesion with water were estimated using apparent contact angle measurements.

\section{Experimental}

\section{Pulps, kappa and viscosity}

Nine Eucalyptus grandis kraft pulp samples were obtained by digesting wood chips in a 20 L laboratory reactor using active alkali (AA) 15.5, 18.1, 19.4, 20.7, 22.0, $23.3,25.9,28.5$ and $31.1 \%(\mathrm{~m} / \mathrm{v})$ as $\mathrm{NaOH}$. The reactor conditions used in all experiments were: pulping temperature $165 \pm 2{ }^{\circ} \mathrm{C}$, heating rate $2.8 \pm 0.1^{\circ} \mathrm{C} \mathrm{min}^{-1}$, sulfidity $27.2 \pm 0.1 \%$ as $\mathrm{NaOH}$, liquor-wood ratio $4: 1$, $\mathrm{H}$-factor $400 \pm 20$ and $1000 \mathrm{~g}$ (o.d.) of chips. After pulping, the unbleached pulps were washed with tap water until the $\mathrm{pH}$ of the filtrate was proximate 6.8 to simulate industrial conditions. Kappa and viscosity were determined according to TAPPI methods T236:85 and T230:94, respectively. Pulp hand sheets were prepared in a Rapid
Köthen apparatus using deionised water and properly conditioned at the temperature of $23 \pm 1^{\circ} \mathrm{C}$ and relative humidity of $50 \pm 2 \%$ prior to FTIR spectrometry and contact angle measurements. Samples were identified according to the AA used in pulping as H15, H18, H19, H21, H22, H23, H26, H29 and H31.

\section{FTIR spectrometry and principal component analysis}

Attenuated total reflectance (ATR) spectra were obtained using a spectrometer Perkin Elmer 1000 equipped with a deuterated triglycine sulphate (DTGS) detector and coupled to a SpectraTech HATR accessory (ZnSe crystal). An incident angle of $45^{\circ}$, spectral resolution of $4 \mathrm{~cm}^{-1}$, number of scans of 256 and temperature of $23^{\circ} \mathrm{C}$ were the standard conditions used. The contact between samples and the ATR crystal was kept to a constant level in all measurements. All FTIR spectra were obtained on the wire side of the hand sheets. Principal component analysis (PCA) was used to identify the effects of active alkali in pulping on the FTIR spectra. PCA is a multivariate data analysis method where a matrix $\mathbf{X}$ with $m$ rows and $n$ columns, with each spectrum of a sample being a row and each intensity at a given wavenumber being a column, is decomposed as the sum of outer products of vectors $\mathbf{t}_{\mathbf{i}}$ and $\mathbf{p}_{\mathbf{i}}$ plus a residual matrix $\mathbf{E}$. The $\mathbf{t}_{\mathbf{i}}$ vectors are known as scores and give information on how the spectra are related to each other. The $\mathbf{p}_{\mathbf{i}}$ vectors are known as loadings and give information on how the spectral intensities are related to each other, i.e., gives a sub-spectrum of a data set. A detailed description of PCA method can be found in the literature. ${ }^{20}$ The ATR spectra were initially pre-processed using a Savitsky-Golay smoothing ${ }^{21,22}$ and then normalized using the position at $1936 \mathrm{~cm}^{-1}$. A 9 x 601 data matrix was built containing 9 spectra and normalized absorbance at wavenumbers in a range of $800-2000 \mathrm{~cm}^{-1}$ with data points in $2 \mathrm{~cm}^{-1}$ interval. Then, the data matrix was mean centred. No matrix scaling was used and the PCA was performed using a computer program (MATLAB 6.1).

Surface charge, work of adhesion with water and surface energy

Surface charge was determined by direct titration of pulp suspensions in deionized water $\left(5 \mathrm{~g}\right.$ pulp $\left.\mathrm{L}^{-1}\right)$ using a MÜTEK particle charge detector. The polyelectrolyte solution used as titrant was a $1 \mathrm{mmol} \mathrm{L}^{-1}$ cationic polydiallyldimethylammonium chloride (poly-DADMAC) with a molar mass in the range of $1 \times 10^{5}-3 \times 10^{5} \mathrm{Da}$, previously purified by ultrafiltration. ${ }^{23}$ The $\mathrm{pH}$ and conductivity of the pulp suspensions ranged between 6.6-6.9 and 17-20 
$\mu \mathrm{S} \mathrm{cm}^{-1}$, respectively. Apparent work of adhesion with water $\left(\mathrm{W}_{\mathrm{ap}}\right)$ and its components acid-base $\left(\mathrm{W}_{\mathrm{ap}-\mathrm{AB}}\right)$ and Lifishitzvan der Waals $\left(\mathrm{W}_{\text {ap-LW}}\right)$ were estimated from $\theta_{\text {ap }}$ determinations on hand sheet surfaces using water and diiodomethane. Apparent surface energy $\left(\sigma_{\text {ap }}\right)$ was estimated using diiodomethane, $\alpha$-bromo-naphthalene and benzaldehyde as probe liquids for $\theta_{\text {ap }}$ measurements and a Zisman plot method. ${ }^{17}$ Hand sheets were previously conditioned at a temperature of $23 \pm 1^{\circ} \mathrm{C}$ and relative humidity of $50 \pm 2 \%$ for 6 hours. Liquids employed as probes were conditioned in the same way. The water was distilled twice in a quartz device and treated in a Nanopure deionization system with a subsequent purge of helium for $20 \mathrm{~min}$. Diiodomethane, $\alpha$-bromo-naphthalene and benzaldehyde were purified by vacuum distillation. The surface tensions of water $\left(\sigma=72.4 \mathrm{~mJ} \mathrm{~m}^{-2}\right.$ at $\left.23{ }^{\circ} \mathrm{C}\right)$, diiodomethane $\left(\sigma=72.4 \mathrm{~mJ} \mathrm{~m}^{-2}\right.$ at $\left.23{ }^{\circ} \mathrm{C}\right)$, $\alpha$-bromonaphthalene $\left(\sigma=44.5 \mathrm{~mJ} \mathrm{~m}^{-2}\right.$ at $\left.23{ }^{\circ} \mathrm{C}\right)$ and benzaldehyde $\left(\sigma=38.3 \mathrm{~mJ} \mathrm{~m}^{-2}\right.$ at $\left.23{ }^{\circ} \mathrm{C}\right)$ were checked using a ring tensiometer. The $\theta_{\text {ap-DIM }}$ values were used for estimation of $\mathrm{W}_{\text {ap-LW}}$. The $\sigma_{\mathrm{L}-\mathrm{LW}}$ assumed for water was $22.4 \mathrm{~mJ} \mathrm{~m}^{-2}$ at $23^{\circ} \mathrm{C} .{ }^{5}$ Measurements of $\theta_{\text {ap }}$ were made in a FIBRO DAT 1000 system. A drop of $3 \mu \mathrm{L}$ of liquid probe was applied automatically by a liquid delivery system using a short stroke from an electromagnet. The parameters that control the stroke intensity are carefully optimized to avoid oscillation of the drop height immediately after application. The images of the drop in contact with the hand sheets were captured by a video camera at time intervals of $20 \mathrm{~ms}$ and shutter opening of $1 \mathrm{~ms}$. The captured images were evaluated by an image analysis system and $\theta_{\text {ap }}$ was calculated. A standard distance excluded from analysis was defined by determination of thickness using an electronic micrometer on 10 different hand sheet areas. The contact time used in all experiments was $0.1 \mathrm{~s}$ and a set of 10 determinations on each hand sheet was measured. Calibration and other details can be found in a standard method (TAPPI method T 588:97).

\section{Results and Discussion}

\section{Effects of kraft pulping on fibre surface chemistry as analysed by FTIR and PCA}

Kappa number and viscosity are routine parameters in the pulp and paper industry to monitor the extent of lignin removal and carbohydrate degradation by pulping, respectively. According to kappa number and viscosity data present in Figure 1, lignin was extensively removed and cellulose degradation increased according to the levels of AA used in pulping. Lignin was removed by cleavage of $\alpha$-and $\beta$-aril-ether bonds between phenyl propane units and subsequent dissolution in the pulping liquor, while cellulose was degraded by alkaline hydrolysis at high temperatures. It should be mentioned that the variation of AA aiming at changing the fibre chemistry was based on previous experiments using a factorial design and fast pulping cycles. $^{24}$

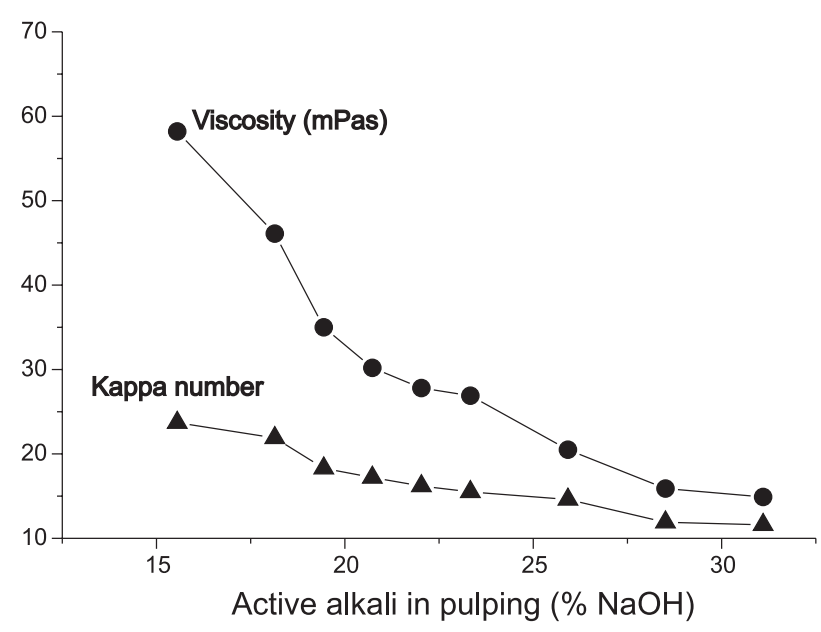

Figure 1. Viscosity and kappa number of pulps obtained using different levels of active alkali in pulping.

The effects of AA on the surface composition of pulps were assessed by FTIR-ATR combined with PCA. The average sampling depth of this technique is $1 \mu \mathrm{m}$, what corresponds to an external layer of $17 \%$ of the fibre wall thickness of eucalyptus kraft pulp. ${ }^{25}$ The ATR normalized spectra of the different pulps in the region of 800-2000 $\mathrm{cm}^{-1}$ are present in Figure 2. It was possible to observe significant changes on ATR spectra when different AA was used. The changes were assessed by PCA. The PCA score plot of the matrix containing spectral data showed that samples obtained with different AA in pulping were clearly separated by the PC1 (Figure 3). This PC described $94.1 \%$ of the variation in the data set and separated samples H15 and H31 in clear opposite positions located in different quadrants.

The loads plot using the PC1 versus the variable number converted to wavenumber gave a sub-spectrum of the data set (Figure 4). This sub-spectrum gave information on what wavenumbers most contributed to the separation of pulp samples according the PC1 value. Characteristic peaks of lignin $\left(\mathrm{C}=\mathrm{C}\right.$ of aromatic at $1595 \mathrm{~cm}^{-1}, 1550 \mathrm{~cm}^{-1}$ and $1500 \mathrm{~cm}^{-1}$; C-O-C of aryl-ether at $1225 \mathrm{~cm}^{-1}$ and 1263 $\mathrm{cm}^{-1}, \mathrm{C}-\mathrm{O}-\mathrm{C}$ of allyl-ether at $1137 \mathrm{~cm}^{-1}$ and $1188 \mathrm{~cm}^{-1}, \mathrm{C}-\mathrm{H}$ of aromatic at $820 \mathrm{~cm}^{-1}, 850 \mathrm{~cm}^{-1}$ and $930 \mathrm{~cm}^{-1}$ ) dominated the sub-spectrum. The PCA sub-spectrum clearly showed that surface lignin was removed when AA was increased. Interestingly, no lignin deposition seemed to occur. Other 


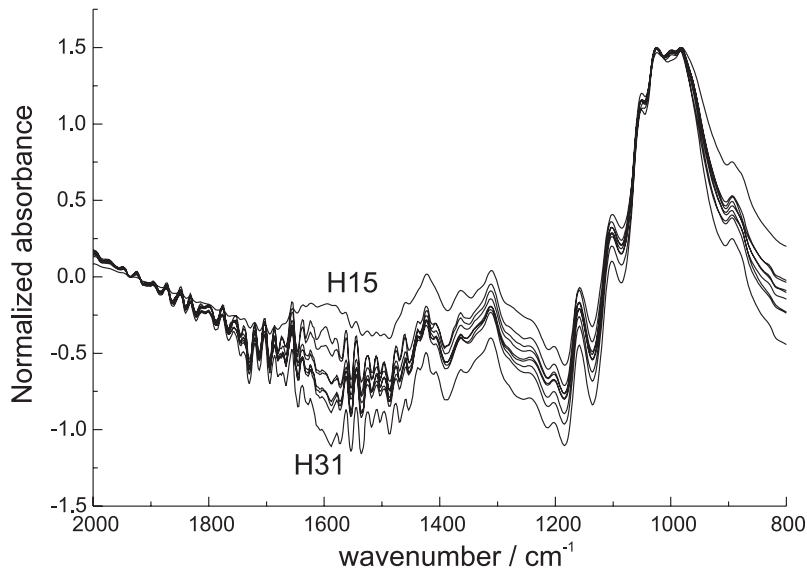

Figure 2. Normalized FTIR-ATR spectra of hand sheets prepared with pulps obtained by using different levels of active alkali in pulping.

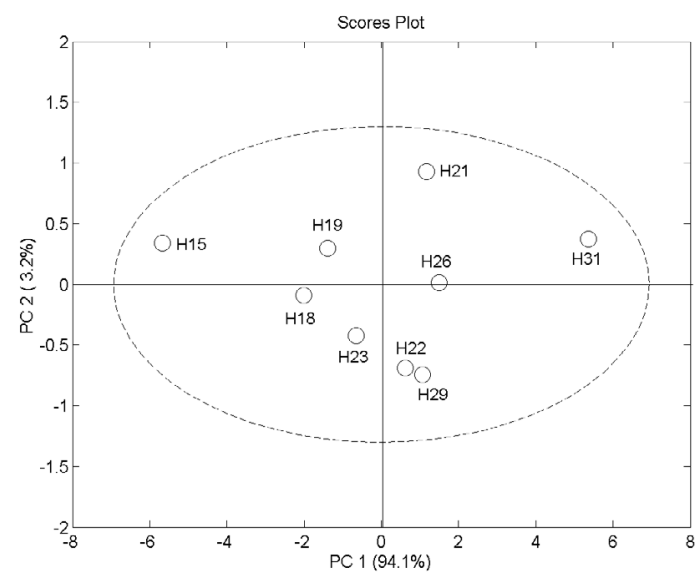

Figure 3. Scores plot of FTIR-ATR spectra of different pulp samples. Spectra were previously normalized and the data matrix was only mean centred. The circle showed that no outlier was present.

interesting observation was the effect on carbohydrates. Peaks of cellulose and hemicelluloses (C-O of primary alcohol at $1038 \mathrm{~cm}^{-1}$, C-O of secondary alcohol at 1088 $\mathrm{cm}^{-1}$ ) seemed to be unaffected by AA indicating a exposure of carbohydrates in parallel to lignin removal. The peaks of $\mathrm{C}-\mathrm{H}$ at $1388 \mathrm{~cm}^{-1}$ and $1463 \mathrm{~cm}^{-1}$ also indicated extractive removal, but as the extractives content in eucalyptus is very low the influence of detection limit of FTIR-ATR cannot be discarded. ${ }^{26}$ The FTIR-ATR findings could be compared with a previous investigation reported for these samples using time-of-flight secondary ion mass spectrometry (ToF-SIMS) and X-ray photoelectron spectroscopy (XPS) (Table 1a and 1b). ${ }^{27}$ The removal of lignin and exposure of carbohydrates was clear as indicated by surface coverage using XPS and the ToF-SIMS peak ratio. Evidently, there are differences in the surface depth probed by these techniques. Thus, our results showed that the effects of kraft pulping on lignin and carbohydrates are apparently even in a layer of $1 \mathrm{~nm}$ to $1 \mu \mathrm{m}$.

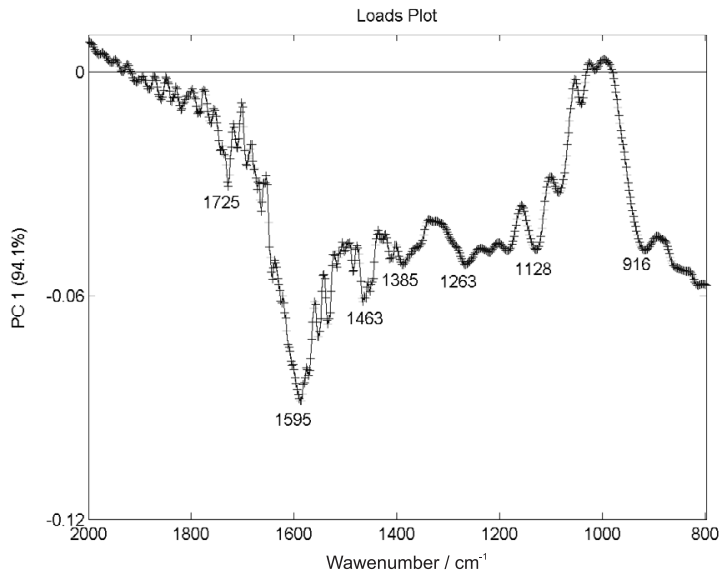

Figure 4. Loads plot for a data matrix containing FTIR-ATR spectra of different pulp samples.

Effects of kraft pulping on interfacial properties

The increase in AA reduced the surface charge in pulps, probably due to removal of lignin and uronic acid side groups in xylan (Figure 5). Other explanation may be the sorption of relocated xylan onto fibre surfaces after removal of its side groups by reactions in the pulping liquor. ${ }^{24}$ Additionally, the surface charge results indicated that the formation of metasaccharinic acids in cellulose ${ }^{29}$ appeared to occur in inner regions of the fibre wall. This was reasonable considering that the penetration of cooking liquor is believed to be through the fibre lumen. ${ }^{30}$

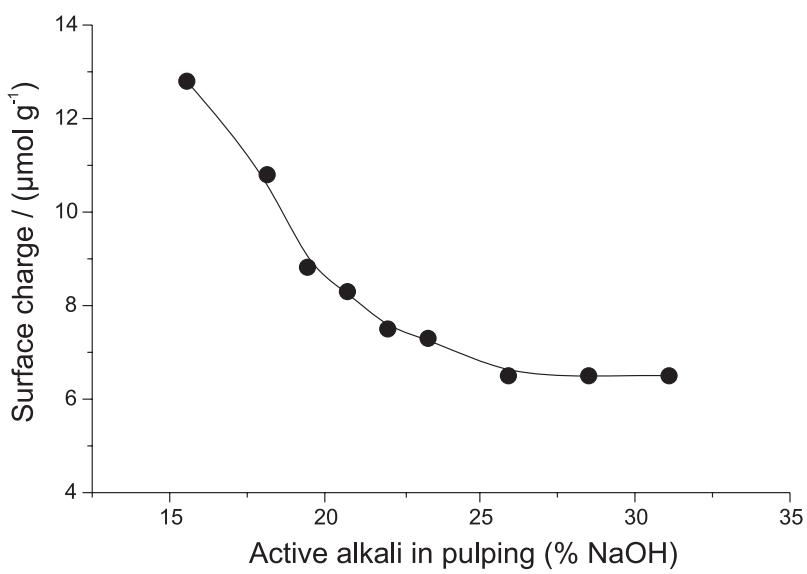

Figure 5. Effects of AA in pulping on surface charge as determined by direct titration of fibres with a high molar mass polyelectrolyte.

The $\theta_{\text {ap }}$ measured for the pulp samples and different probe liquids is present in Table 2. The coefficient of variation $(\mathrm{CV})$ was also calculated. No effects of pulping were observed on the $\theta_{\text {ap-DIM }}$, which was lower than $\theta_{\text {ap-WA }}$. This was evidence that the eventual variations in hand sheet roughness did not disturb the $\theta_{\text {ap }}$ measurement significantly. Hand sheets are isotropic and no influence 
Table 1a. ToF-SIMS and XPS results reported by Fardim and Durán. ${ }^{27}$ The peak ratios in ToF-SIMS were calculated after normalization by the spectrum total counts.

\begin{tabular}{|c|c|c|c|}
\hline Component & $\begin{array}{r}\text { Peaks in } \\
\text { Peak }\end{array}$ & Peaks in TOF-SIMS spectra & $\begin{array}{r}\text { Peak Ratios } \\
\text { H29/H15 }\end{array}$ \\
\hline \multicolumn{4}{|c|}{ Carbohydrates } \\
\hline \multirow[t]{2}{*}{ Cellulose } & $127+$ & $\mathrm{C}_{6} \mathrm{H}_{7} \mathrm{O}_{3}^{+}$ & 1.3 \\
\hline & $145+$ & $\mathrm{C}_{6} \mathrm{H}_{9} \mathrm{O}_{4}^{+}$ & 1.2 \\
\hline \multirow[t]{2}{*}{ Xylan } & $115+$ & $\mathrm{C}_{5} \mathrm{H}_{7} \mathrm{O}_{3}^{+}$ & 1.3 \\
\hline & $133+$ & $\mathrm{C}_{5} \mathrm{H}_{9} \mathrm{O}_{4}^{+}$ & 1.1 \\
\hline \multicolumn{4}{|l|}{ Lignin } \\
\hline & $137+$ & $\mathrm{C}_{8} \mathrm{H}_{9} \mathrm{O}_{2}^{+}$ & 0.9 \\
\hline & $151+$ & $\mathrm{C}_{8} \mathrm{H}_{7} \mathrm{O}_{3}^{+}$ & 0.7 \\
\hline & $167+$ & $\mathrm{C}_{9} \mathrm{H}_{11} \mathrm{O}_{3}^{+}$ & 0.8 \\
\hline & $181+$ & $\mathrm{C}_{9} \mathrm{H}_{9} \mathrm{O}_{4}^{+}$ & 0.6 \\
\hline
\end{tabular}

Extractives

Free Fatty acids

Pentadecanoic

Pentadecanoic 243+

Palmitic

$225+$

Oleic

$257+$

$239+$

$283+$

Stearic

$265+$

Lignoceric

$285+$

$267+$

$369+$

$351+$

$339+$

Pentacosanoic

$383+$

$365+$

$355+$

Fatty acid salts

Calcium

Myristate

Pentadecanoate

$281+$

Palmitate

$523+$

Stearate

$296+$

$551+$

$323+$

Sodium

Oleate

Eicosenoate

Lignocerate

Hexadecanoate

Sterols

Sitosterol

$304+$

$305+$

$332+$

$333+$

$391+$

$413+$

$441+$

$415+$

$414+$

$397+$

Sitostanol

Oxo-sitosterol
$\mathrm{C}_{14} \mathrm{H}_{29} \mathrm{O}_{2}^{+}$

$\mathrm{C}_{14} \mathrm{H}_{27} \mathrm{O}^{+}$

$\mathrm{C}_{15} \mathrm{H}_{31} \mathrm{O}_{2}{ }^{+}$

$\mathrm{C}_{15} \mathrm{H}_{29} \mathrm{O}^{+}$

$\mathrm{C}_{16} \mathrm{H}_{33} \mathrm{O}_{2}^{+}$

$\mathrm{C}_{16} \mathrm{H}_{31} \mathrm{O}^{+}$

$\mathrm{C}_{18} \mathrm{H}_{35} \mathrm{O}_{2}^{+}$

$\mathrm{C}_{18} \mathrm{H}_{33} \mathrm{O}^{+}$

$\mathrm{C}_{18} \mathrm{H}_{37} \mathrm{O}_{2}^{+}$

$\mathrm{C}_{18} \mathrm{H}_{35} \mathrm{O}^{+}$

$\mathrm{C}_{24} \mathrm{H}_{49} \mathrm{O}_{2}^{+}$

$\mathrm{C}_{24} \mathrm{H}_{47} \mathrm{O}^{+}$

$\mathrm{C}_{23} \mathrm{H}_{47} \mathrm{O}^{+}$

$\mathrm{C}_{25} \mathrm{H}_{51} \mathrm{O}_{2}^{+}$

$\mathrm{C}_{25} \mathrm{H}_{49} \mathrm{O}^{+}$

$\mathrm{C}_{24} \mathrm{H}_{51} \mathrm{O}^{+}$

0.7

0.7

0.9

0.7

0.7

0.8

0.8
1.2

1.1

1.4

0.7

1.7

0.6

0.9

0.5

0.7

0.9

$\mathrm{C}_{14} \mathrm{H}_{28} \mathrm{O}_{2} \mathrm{Ca}^{+} \quad 0.7$

$\mathrm{C}_{15} \mathrm{H}_{29} \mathrm{O}_{2} \mathrm{Ca}^{+} \quad 0.7$

$\mathrm{C}_{30} \mathrm{H}_{59} \mathrm{O}_{4} \mathrm{Ca}^{+} \quad 0.5$

$\mathrm{C}_{16} \mathrm{H}_{32} \mathrm{O}_{2} \mathrm{Ca}^{+} \quad 0.5$

$\mathrm{C}_{32} \mathrm{H}_{63} \mathrm{O}_{4} \mathrm{Ca}^{+} \quad 0.4$

$\mathrm{C}_{18} \mathrm{H}_{35} \mathrm{O}_{2} \mathrm{Ca}^{+} \quad 0.6$

$\mathrm{C}_{18} \mathrm{H}_{36} \mathrm{O}_{2} \mathrm{Ca}^{+} \quad 0.8$

$\mathrm{C}_{18} \mathrm{H}_{33} \mathrm{O}_{2} \mathrm{Na}^{+} \quad 0.3$

$\mathrm{C}_{18} \mathrm{H}_{34} \mathrm{O}_{2} \mathrm{Na}^{+} \quad 0.4$

$\mathrm{C}_{20} \mathrm{H}_{38} \mathrm{O}_{2} \mathrm{Na}^{+} \quad 0.3$

$\mathrm{C}_{24} \mathrm{H}_{48} \mathrm{O}_{2} \mathrm{Na}^{+}{ }_{2} \quad 0.8$

$\mathrm{C}_{26} \mathrm{H}_{51} \mathrm{O}_{2} \mathrm{Na}^{+}{ }_{2}$

$\mathrm{C}_{29} \mathrm{H}_{51} \mathrm{O}^{+} \quad 0.7$

$\mathrm{C}_{29} \mathrm{H}_{50} \mathrm{O}^{+} \quad 0.9$

$\mathrm{C}_{29} \mathrm{H}_{49}{ }^{+} \quad 0.7$

$\mathrm{C}_{29} \mathrm{H}_{52} \mathrm{O}^{+} \quad 0.7$

$\mathrm{C}_{29} \mathrm{H}_{50}{ }^{+} \quad 0.8$

$\mathrm{C}_{29} \mathrm{H}_{48} \mathrm{O}_{2}^{+} \quad 0.9$

$\mathrm{C}_{29} \mathrm{H}_{47} \mathrm{O}^{+} \quad 0.4$
$\mathrm{C}_{28} \mathrm{H}_{55} \mathrm{O}_{4} \mathrm{Ca}^{+} \quad 0.9$

$\mathrm{C}_{20} \mathrm{H}_{37} \mathrm{O}_{2} \mathrm{Na}^{+} \quad 0.2$

$\mathrm{C}_{24} \mathrm{H}_{47} \mathrm{O}_{2} \mathrm{Na}^{+} \quad 0.7$
Table 1b. Surface coverage (\%-area) of carbohydrates ( $\phi$ carb), lignin $(\phi l i g)$ and extractives ( $\phi$ ext) were estimated using XPS $^{28}$

\begin{tabular}{lcccc}
\hline & \multicolumn{4}{c}{ Surface coverage by XPS } \\
\cline { 2 - 5 } & H15 & H18 & H23 & H29 \\
\hline$\phi$ carb & 56 & 70 & 72 & 84 \\
$\phi$ lig & 44 & 30 & 28 & 16 \\
$\phi$ ext & 2.0 & 5.3 & 5.2 & 12.5 \\
\hline
\end{tabular}

of fibre orientation was present. The $\theta_{\text {ap-DIM }}$ values were very similar as previously obtained for hardwoods using single fibers and the Wilhelmy method., ${ }^{5,31}$ The $\mathrm{W}_{\text {ap }}$ and its components $\mathrm{W}_{\text {ap-AB }}$ and $\mathrm{W}_{\text {ap-LW }}$ were estimated and presented in Figure 6. The $\mathrm{W}_{\mathrm{ap}}$ was dependent on the AA used in pulping. The major contributor for $\mathrm{W}_{\text {ap }}$ was the $\mathrm{W}_{\text {ap-LW }}$ component, however, the $\mathrm{W}_{\text {ap-AB }}$ gradually increased with AA until equalizing the $\mathrm{W}_{\text {ap-LW}}$. This was a clear indication that sites for hydrogen bonding were made accessible by pulping. Interestingly, the dispersion forces represented by $\mathrm{W}_{\text {app-LW }}$ did not change.

The apparent surface energy $\left(\sigma_{\text {ap }}\right)$ was estimated by a Zisman plot using the $\cos \theta_{\text {ap }}$ of different liquid probes. The $\sigma_{\mathrm{ap}}$ also increased with AA in pulping (Figure 7), probably due to removal of lignin and exposure of carbohydrates. The $\sigma_{\text {ap }}$ for samples with low kappa number was similar as reported by using IGC for other eucalypts samples at the same kappa level. ${ }^{6}$ It is conceivable that the adhesion of two components with high surface energy such as cellulose $\left(55 \mathrm{~mJ} \mathrm{~m}^{-2}\right)^{32}$ and lignin $\left(47 \mathrm{~mJ} \mathrm{~m}^{-2}\right)^{33}$ in the fibre wall tends to lower considerably the free energy of the system. However, during pulping lignin is extensively removed and exposure of carbohydrates generates sites with relative high surface energy. At the same time, molecules with low surface energy, e.g. wood extractives, tend to segregate to the surface and minimize the total surface free energy. The fact that extractives such as fatty acids have a hydrophobic tail and a hydrophilic head group should also be considered. Thus, a migration of extractives to sites of high surface energy and surface mobility according to the character of the interface involved are due to occur. Evidence of extractive migration and surface mobility can be observed when $\mathrm{W}_{\text {ap }}, \mathrm{W}_{\text {ap-AB }}, \sigma_{\text {ap }}$ and surface charge are taken into account and consequently a hypothesis is put forward: during pulping lignin and uronic acids are removed, the surface charge is reduced and carbohydrate sites of relative high surface energy are formed. Then, high energy sites in cellulose and hemicelluloses are occupied by extractive molecules that migrate from different regions inside the fibre wall or from external surfaces. This is thermodynamically favoured because the total surface 
Table 2. Apparent contact angles $\left(\theta_{\text {ap }}\right)$ of different probe liquids measured on hand sheet surfaces. Results are average of 10 measurements and coefficient of variation is given in parentheses. Water (WA), diiodomethane (DIM), a-bromo naphthalene (BR) and benzaldehyde (BZ)

\begin{tabular}{ccccc}
\hline Sample & $\theta_{\text {ap-WA }}$ & $\theta_{\text {ap-DIM }}$ & $\theta_{\text {ap-BR }}$ & $\theta_{\text {ap-BZ }}$ \\
\hline H15 & $88.7(1)$ & $29.9(4)$ & $25.7(3)$ & $22.4(6)$ \\
H18 & $72.4(3)$ & $24.7(6)$ & $23.0(7)$ & $18.1(6)$ \\
H19 & $60.8(1)$ & $29.3(6)$ & $24.0(5)$ & $17.5(9)$ \\
H21 & $67.1(4)$ & $28.3(5)$ & $23.1(5)$ & $19.6(8)$ \\
H22 & $63.6(2)$ & $26.5(6)$ & $20.8(8)$ & $17.4(9)$ \\
H23 & $67.9(6)$ & $25.9(7)$ & $22.5(6)$ & $13.3(10)$ \\
H26 & $48.9(6)$ & $28.3(5)$ & $21.3(7)$ & $18.1(7)$ \\
H29 & $42.0(5)$ & $29.0(5)$ & $20.3(7)$ & $17.1(8)$ \\
H31 & $44.3(5)$ & $29.5(4)$ & $24.7(5)$ & $16.5(9)$ \\
\hline
\end{tabular}

energy of the system is minimized. In a fiber-water interface, there is surface mobility and the hydrophilic head of fatty acids will be oriented towards the water phase. As a consequence $\mathrm{W}_{\text {ap }}$ and $\mathrm{W}_{\text {ap- } \mathrm{AB}}$ increase due to a combination of lignin removal, exposure of carbohydrates and relocation of extractives. In a fiber-solvent interface, there is also surface mobility, but the hydrophobic chains are oriented towards the solvent, as a result the $\sigma_{a p}$ is lower than the expected for solvent extracted eucalyptus pulps, i.e., nearly $50-60 \mathrm{~mJ} \mathrm{~m}^{-2}{ }^{6,34}$

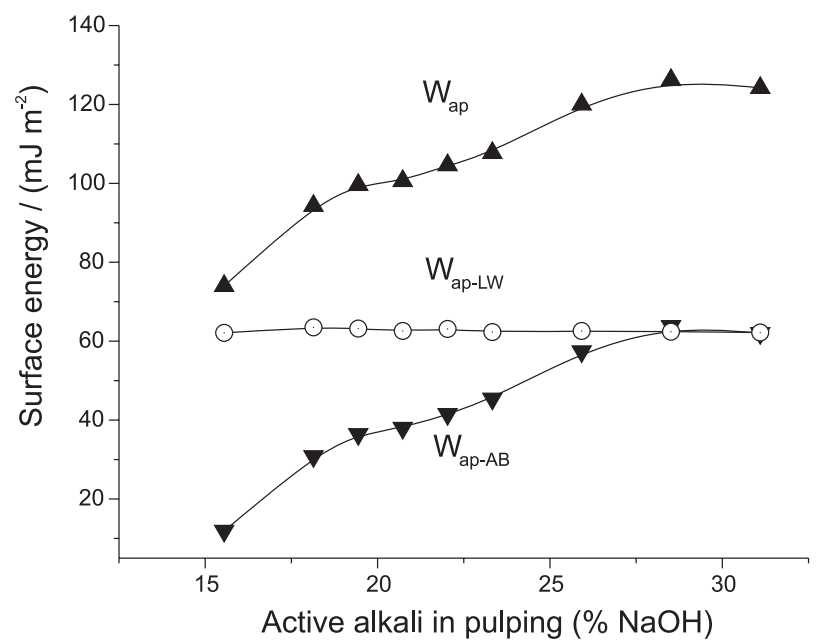

Figure 6. Effects of $\mathrm{AA}$ in pulping on $\mathrm{W}_{\text {ap }}, \mathrm{W}_{\text {ap- } \mathrm{LW}}$ and $\mathrm{W}_{\mathrm{ap}-\mathrm{AB}}$ as estimated by contact angle. The increase in $\mathrm{W}_{\text {ap }}$ was a clear contribution of $\mathrm{W}_{\mathrm{ap}-\mathrm{AB}}$.

\section{Influences of interfacial properties on bleaching sequences and pulp mechanical properties}

Bleaching is usually done by addition of chemicals dissolved in water to a pulp suspension. During bleaching an interface fibre-water is present; however, the role of interfacial properties in bleaching is practically unexplored. Bleaching has been treated as a liquid phase reaction and consumption of bleaching chemicals as dependent on contents of residual lignin and hexenuronic

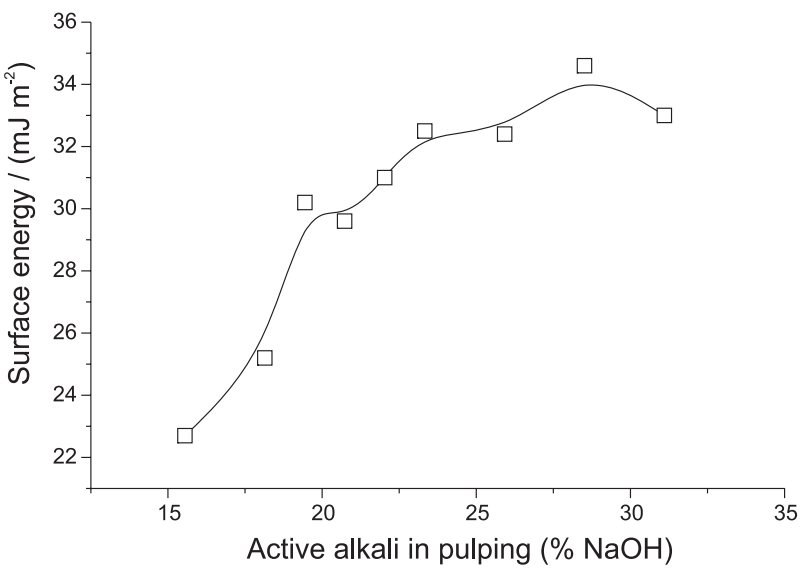

Figure 7. Effects of AA in pulping on $\sigma_{\text {ap }}$ as estimated by the Zisman method.

acid in pulp. Carbohydrates are degraded in bleaching and negative effects on mechanical and optical properties were extensively reported. Some attractive alternatives to be investigated are the utilization of surface active agents to protect the carbohydrate sites and the modification of interfacial properties to improve the adhesion between reagents and fibre phases. There is a great demand for development of fast bleaching sequences for high brightness pulps. At the same time, bleached pulps with special properties such as improved wettability and mechanical properties can be designed in bleaching. The impact of interfacial properties on reaction kinetics, consumption of chemicals and pulp bleachability is a suggestion for future work.

Mechanical properties of pulps are affected by fibreto-fibre bonding and consequently by changes in interfacial properties during pulping, bleaching and refining. The utilization of fast pulping cycles, low AA and thin eucalyptus chips was suggested to reduce the xylan relocation, improving fibre wall swelling and flexibility and thus contributing to fibre-to-fibre bonding. ${ }^{24}$ More recently, it was also suggested that surface extractives can be detrimental to mechanical properties due to reduction of fibre-to-fibre bonding. ${ }^{35}$ Hence, according to the hypothesis presented here, any strategy to be developed for fibre modification or even optimization of pulping, bleaching and refining conditions should consider the migration and relocation of extractives onto fibre interfaces. Otherwise, no improvement in mechanical properties will be properly achieved.

\section{Conclusions}

We investigated the effects of kraft pulping on surface charge, work of adhesion with water and surface energy 
of pulp fibres. The increase in active alkali in pulping reduced the surface charge, increased of work of adhesion with water and surface energy, and improved the removal of surface lignin. The acid-base component was the main contributor for increasing in the work of adhesion with water. A hypothesis to clarify the modifications of interfacial properties by kraft pulping was put forward based on a combination of lignin removal, exposure of carbohydrates and surface mobility of extractives. The role of interfacial properties in bleaching sequences, improvement of mechanical properties and development of new pulp products was briefly discussed.

\section{Acknowledgements}

Support from Suzano Papel e Celulose and Åbo Akademi Process Chemistry Centre is acknowledged.

\section{References}

1. Barzyk, D.; Page, D. H.; J. Pulp Pap. Sci. 1997, 23, 59.

2. Etzler, F. M.; Conners J. J. In Surface Analysis of Paper; Conners, T.E.; Banerjee, S., eds.; CRC: Boca Raton, 1995, p. 90-108.

3. Duke, C. B.; Noolandi, J.; Thieret, T.; Surf. Sci. 2002, 500, 1005.

4. Adamson, A. W.; Physical Chemistry of Surfaces, $5^{\text {th }}$ ed., Wiley: New York, 1990.

5. Berg, J.C.; Nord. Pulp Pap. Res. J. 1993, 8, 75.

6. Shen, W.; Parker, I.H.; Sheng, Y.J.; J. Adhesion Sci. Technol. 1998, 12, 161.

7. Carlsson, G.; Ström,G.; Nord. Pulp Pap. Res. J. 1995, $10,17$.

8. Mejier, M.; Haemers, S.; Cobben, W.; Militz, H.; Langmuir 2000, 16, 9352.

9. Shen, W.; Filonanko, Y.; Truong, I. H.; Parker, N.; Brack, P.; Pigram, P.; Liesegang, J.; Colloid Surface A 2000, 173, 117.

10. Kwok, D.; Neuman, W.; J. Phys. Chem. B 2000, 104, 741.

11. Gerdes, S.; Cazabat, A.; Ström,G.; Langmuir 1997, 13, 7258.

12. Della Volpe, C.; Penati, A.; Peruzzi, R.; Siboni, S.; Toniolo, L.; Colombo, C.; J. Adhes. Sci. Technol. 2000, 14, 273.
13. Neimark, A.; J. Adhes. Sci. Technol. 2000, 13, 1137.

14. McHale, G.; Rowan, S.M.; Newton, M.I.; Käb, N.A.; J. Adhes. Sci. Technol. 2000, 13, 1457.

15. Fowkes, F.M.; McCarthy, D.C.; Mostafa, M.A.; J. Colloid Interface Sci 1980, 78, 200.

16. Fox, H.W.; Zisman, W.A.; J. Colloid Interface Sci. 1952, 7, 109.

17. Jacob, P.; Berg, J.; Tappi J. 1993, 76, 105.

18. Wågberg, L.; Ödberg, L.; Glad.Normark, G.; Nord. Pulp Pap. Res. J. 1989, 4, 71.

19. Rojas, O. J.; Ernstsson, M.; Neuman, R. D.; Claesson, P. M.; J. Phys. Chem. B 2000, 104, 10032.

20. Wold, S.; Esbensen, K.; Geladi, P.; Chemometr. Intell. Lab. Syst. 1987, 2, 37.

21. Savitzky, A.; Golay, M.J.E.; Anal. Chem. 1964, 36, 1627.

22. Madden, H. H.; Anal. Chem. 1978, 50, 1383.

23. Laine, J.; Buchert, J.; Viikari, L.; Stenius, P.; Holzforschung 1996, 50, 208.

24. Fardim, P.; Durán, N.; J. Braz. Chem. Soc. 2004, 15, 514.

25. Fardim, P.; PhD Thesis, Universidade Estadual de Campinas, Brazil, 1999.

26. Kokkonen, P.; Fardim, P.; Holmbom, B.; Nord. Pulp Pap. Res. J. 2004, 19, 318.

27. Fardim, P.; Durán, N.; Colloid Surf. A 2003, 223, 263.

28. Ström, G.; Carlsson, G.; J. Adhes. Sci. Technol. 1992, 6, 745.

29. Buchert, J.; Tenkanen, M.; Tamminen, T.; Tappi J. 2001, 84, 70.

30. Maloney, T.C.; Paulapuro, H.; J. Pulp Pap. Sci. 1999, 25, 430.

31. Jacob, P.; Berg, J.; Tappi J. 1993, 76, 133.

32. van Oss, C.J.; Interfacial Forces in Aqueous Media, Marcel Dekker: New York, 1994.

33. Belgacem, M. N.; Blayo, A.; Gandini, A.; J. Colloid Interface Sci. 1996, 182, 431.

34. Shen, W.; Parker, I. H.; Cellulose 1999, 6, 41.

35. Fardim, P.; Durán, N.; J. Braz. Chem. Soc. 2005, 16, 163.

Received: September 24, 2004 Published on the web: July 14, 2005

FAPESP helped in meeting the publication costs of this article. 